\title{
Structural, Optical and Antimicrobial Analysis of Nickel Doped HAp Synthesized by Solgel Method for Biomedical Applications
}

\author{
Saranya S*, Muthuselvi S and Prema Rani M \\ Department of Physics, The Madura College, Madurai-11, Tamilnadu, India
}

\begin{abstract}
Hydroxyapatite ( $\mathrm{HAp})$ having chemical formula $\mathrm{Ca}_{10}\left(\mathrm{PO}_{4}\right)_{6}(\mathrm{OH})_{2}$ is the main chemical component of human bone tissue $(70 \%)$, to cope up with the bone response as a bio active material. In this study Ni doped HAp powder with triclinic phase was synthesized by sol-gel method, by doping Ni of different concentrations $(0.02,0.04,0.06$, and 0.08$)$. The various properties due to different concentration of $\mathrm{Ni}$ in HAp were characterized by X-ray diffraction analysis (XRD), Energy dispersive $x$-ray spectroscopy (EDX) and Fourier transform spectroscopy (FT-IR). The thermal gravimetric analysis (TGA-DTA) was also carried out to evaluate the stability of the synthesized HAP powder. Antibacterial activity of compounds against microbial pathogens was done using well diffusion method. High antibacterial activity was observed for $\mathrm{Ca}_{0.98} \mathrm{Ni}_{0.02}\left(\mathrm{PO}_{4}\right)(\mathrm{OH})_{2}$. The transmission electron microscopic analysis confirms the presence of the spherical shape morphology of the prepared hydroxyapatite nanoparticle with the particle size of around 20 to $100 \mathrm{~nm}$.
\end{abstract}

Keywords: X-ray diffraction; Hydroxyapatite; Crystallite size; Thermal gravimetric analysis

\section{Introduction}

Hydroxyapatite $(\mathrm{Ca})_{10}\left(\mathrm{PO}_{4}\right)_{6}(\mathrm{OH})_{2} \quad(\mathrm{HAp})$ is an important inorganic biomaterial which has attracted the attention of researchers related to biomaterials field in recent years. Due to its chemical and structural similarity with the mineral phase of bone and teeth, HAp is widely used for hard tissues repair. As a result, this inorganic phosphate has been studied extensively for medical applications in the form of powders. Hydroxyapatite is the dominant inorganic phase in natural bone. Synthetic hydroxyapatite particles, films, coatings, fibers are used extensively in various biomedical applications $[1,2]$. This bioceramic, $\mathrm{Ca}_{10}\left(\mathrm{PO}_{4}\right)_{6}(\mathrm{OH})_{2}$, can be synthesized by sol-gel method is becoming a unique low-temperature technique to produce pure ceramic powders. Recently, hydroxyapatite powders and coatings have been successfully synthesized by the sol gel method [3,4]. Nickel has good mechanical strength and is anti-corrosion. Substitution of Nickel ions for calcium in apatite compounds will increase the mechanical strength and will be a suitable biomaterial for biomedical applications [5].

\section{Experimental Procedure}

In this method two different chemical reactants were used. At first phosphoric pentoxide $\mathrm{P}_{2} \mathrm{O}_{5}$ (Merck) was dissolved in absolute ethanol to form a solution and secondly calcium nitrate tetra hydrate $\mathrm{Ca}_{10}$ $\left(\mathrm{NO}_{3}\right)_{2} \cdot 6 \mathrm{H}_{2} \mathrm{O}$ was also dissolved in ethanol to form $1.67 \mathrm{~mol} / \mathrm{l}$ solution. After this both the solutions were mixed to obtain the desired $\mathrm{Ca} / \mathrm{P}$ molar ratio of 1.67. But rapid addition of any one reagent to another reactant can cause precipitation. Hence the solution was stirred slowly for 45 minutes until the formation of a gel. Further the gel was dried in an electric oven with temperature of $110^{\circ} \mathrm{C}$ in air for 30 minutes. The samples are heated at $600^{\circ} \mathrm{C}$ for $4 \mathrm{~h}$.

\section{Result and Discussion}

\section{Powder XRD studies}

The crystallographic phases of HA powder was determined by $\mathrm{X}$-ray diffractometer (XRD) using a diffractometer in reflection mode with $\mathrm{Cu} \mathrm{Ka}(\lambda=1.54056 \AA)$ radiation. The powder X-ray data set was collected in the $2 \theta$ range from $10^{\circ}$ to $120^{\circ}$ with step size $0.02^{\circ}$ at SAIF,
Cochin, with a monochromatic incident beam of wavelength 1.54056 $\AA$ offering pure $\mathrm{Cu}-\mathrm{Ka}$ radiations. The obtained data was compared with JCPDS and the crystal structure was confirmed as triclinic, with space group of P-1 from the data (JCPDS No. 44-0778). The obtained XRD profile is shown in Figure 1. The peaks indicate the formation of crystalline phase, several peaks of XRD pattern which belongs to the HA powder become more distinct and, also the widths of the peaks become more narrow, which suggests that there is an increase in the crystallinity of powder. The grain size of the prepared samples was determined as $24 \mathrm{~nm}$ by Debye-Scherer formula, $\mathrm{D}=0.9 \lambda / \beta \operatorname{Cos} \theta$, where $\lambda$ is the wavelength of $\mathrm{X}$-rays, $\beta$ is the full width half maximum of the XRD peak, $\theta$ is the Bragg reflection angle. The calculated values of crystallite size for pure and Ni doped hydroxyapatite is given in Table 1.

\section{FT-IR analysis}

The presence of functional groups was confirmed using Fourier transform infrared spectroscopy. The spectrum was recorded in the range of 4000-400 $\mathrm{cm}^{-1}$ using $\mathrm{KBr}$ pellet technique. The resolution of spectrometer was $4 \mathrm{~cm}^{-1}$. The representative FTIR spectrum shows all characteristic absorption peaks of HAp. The FT-IR spectra were obtained over the region $570-3642 \mathrm{~cm}^{-1}$. The FT-IR spectra are shown in Figure 2. The transmittance data is given in Table 2. The first indication for formation of HAp is in the form of a strong complex broad FTIR band centered at about $1000-1100 \mathrm{~cm}^{-1}$ due to symmetric stretching mode of vibration for $\mathrm{PO}_{4}$ group [6]. The crystalline powder generates two characteristic stretching modes of $\mathrm{O}-\mathrm{H}$ bands at about

*Corresponding author: Saranya S, Research Centre, PG, Department of Physics, The Madura College, Madurai-11, Tamilnadu, India, Tel: 0452267 3354; E-mail: premaakumar@gmail.com

Received October 29, 2017; Accepted December 23, 2017; Published January 03, 2018

Citation: Saranya S, Muthuselvi S, Prema Rani M (2018) Structural, Optical and Antimicrobial Analysis of Nickel Doped HAp Synthesized by Solgel Method for Biomedical Applications. J Material Sci Eng 7: 413. doi: 10.4172/21690022.1000413

Copyright: () 2018 Saranya S, et al. This is an open-access article distributed under the terms of the Creative Commons Attribution License, which permits unrestricted use, distribution, and reproduction in any medium, provided the original author and source are credited. 


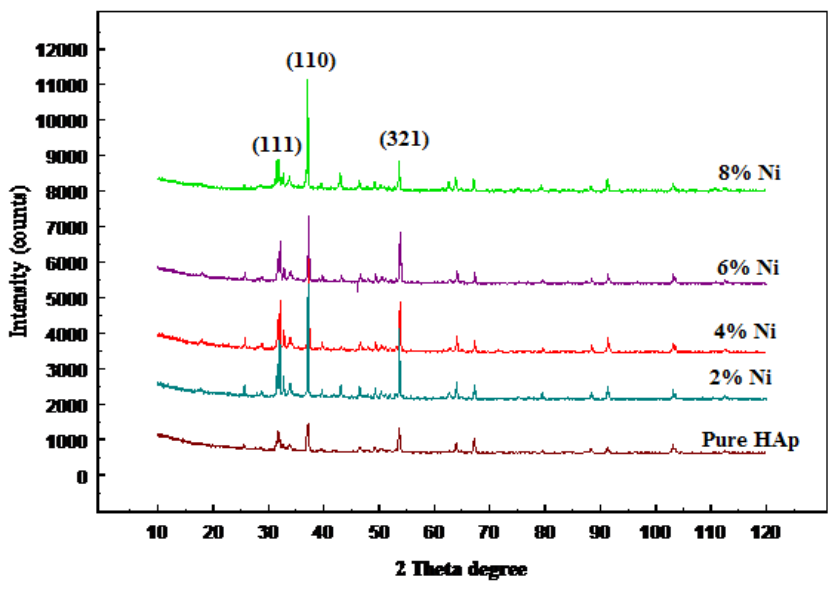

Figure 1: XRD patterns of the pure and Ni doped HAp powders.

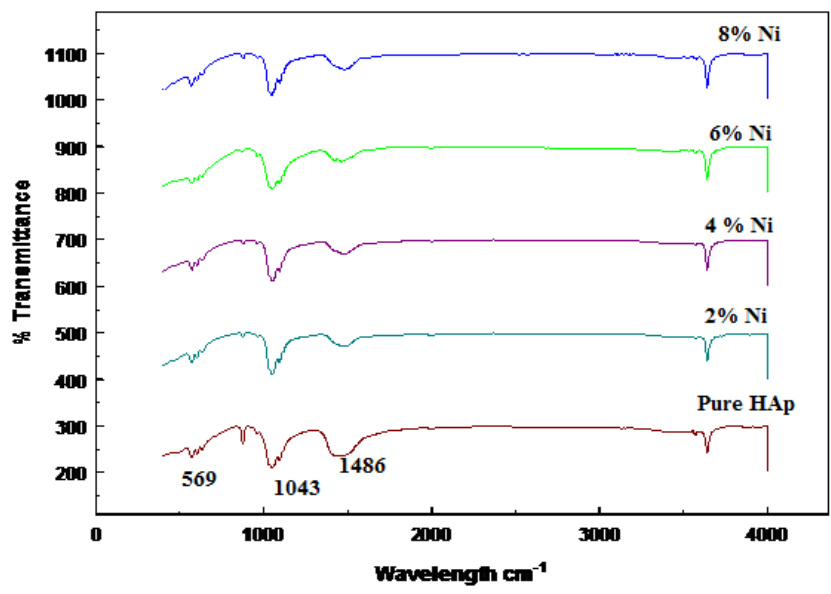

Figure 2: FTIR Spectrum of pure and Ni doped HAp powders.

\begin{tabular}{|c|c|}
\hline Samples & Crystallite Size (nm) \\
\hline Pure $\mathrm{HAp}$ & 28.33 \\
\hline $2 \%$ of $\mathrm{Ni}$ & 28.25 \\
\hline $4 \%$ of $\mathrm{Ni}$ & 25.79 \\
\hline $6 \%$ of $\mathrm{Ni}$ & 23.25 \\
\hline $8 \%$ of $\mathrm{Ni}$ & 15.19 \\
\hline
\end{tabular}

Table 1: Crystallite size of pure HAp and Ni doped HAp powders.

$3642 \mathrm{~cm}^{-1}$ and $3572 \mathrm{~cm}^{-1}$. Also there is an O-P-O bending mode in the HAp at $603.48 \mathrm{~cm}^{-1}$.

\section{Thermal analysis (TGA-DTA)}

TGA and DTA analysis has been done at SAIF, COCHIN. This is occurring because evaporation of water and similarly the other endothermic peaks in the curve related to the removal or addition of other molecules during the synthesis of HAp powder. This is occurring on temperature stability is pure HAp increased with decreased in $\mathrm{Ni}$ doped samples. DTA curve indicate the endothermic reaction. In this thermal gravimetric analysis actual weight losses are observed in the related temperature ranges are $428-421^{\circ} \mathrm{C}$. The first loss is due to the weakly entrapped water in the sample material, the second and third losses resulted from the decomposition of molecules.

\begin{tabular}{|c|c|c|}
\hline Samples & 2 Theta (degrees) & Intensity \\
\hline Pure $\mathrm{HAp}$ & 37.098 & 643 \\
\hline $2 \%$ of $\mathrm{Ni}$ & 37.101 & 1520 \\
\hline $4 \%$ of $\mathrm{Ni}$ & 37.163 & 1853 \\
\hline $6 \%$ of $\mathrm{Ni}$ & 37.254 & 2029 \\
\hline $8 \%$ of $\mathrm{Ni}$ & 37.268 & 2242 \\
\hline
\end{tabular}

Table 2: Intensity and 2 theta degrees values.

\section{Energy dispersive X-ray spectroscopy (EDX)}

The surface morphology and micro structural features of the synthesized HA powder with elemental composition was studied and evaluated by energy dispersive X-ray analysis (EDS). EDS makes use of the X-ray spectrum emitted by a solid sample bombarded with a focused beam of electrons to obtain a localized chemical analysis [7]. Qualitative analysis involves the identification of the lines in the spectrum and is fairly straight forward owing to the simplicity of X-ray spectra. Quantitative analysis (determination of the concentrations of the elements present) entails measuring line intensities for each element in the sample and for the same elements in calibration Standards of known composition [8]. The obtained EDS spectrum is shown in Figure 3. The composition of elements is given in Table 3 and Figure 4. 


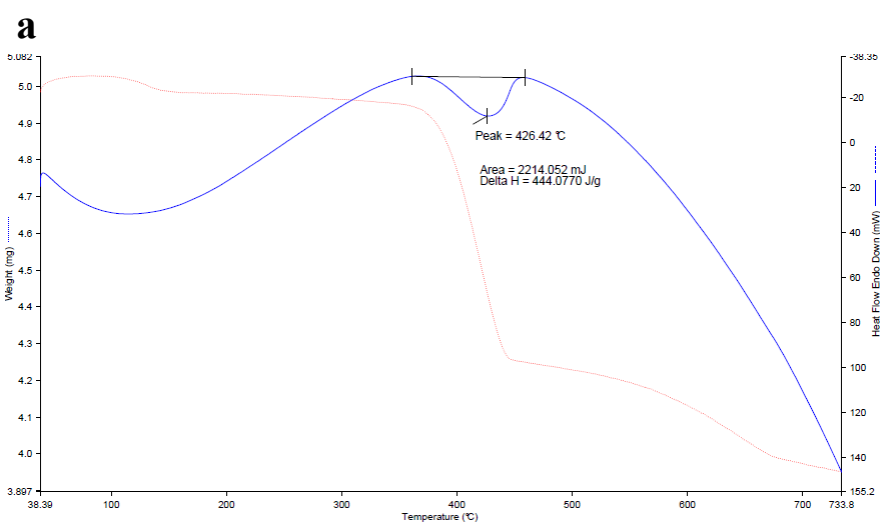

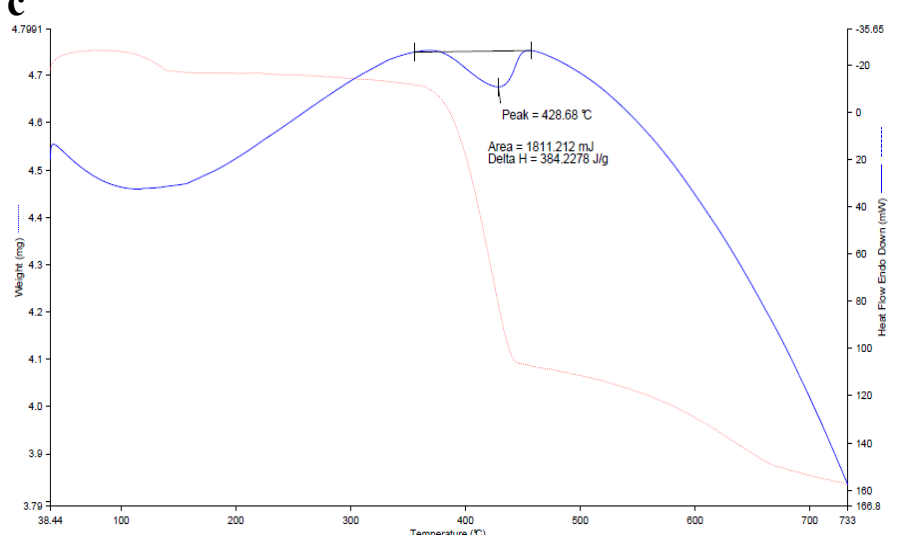

b

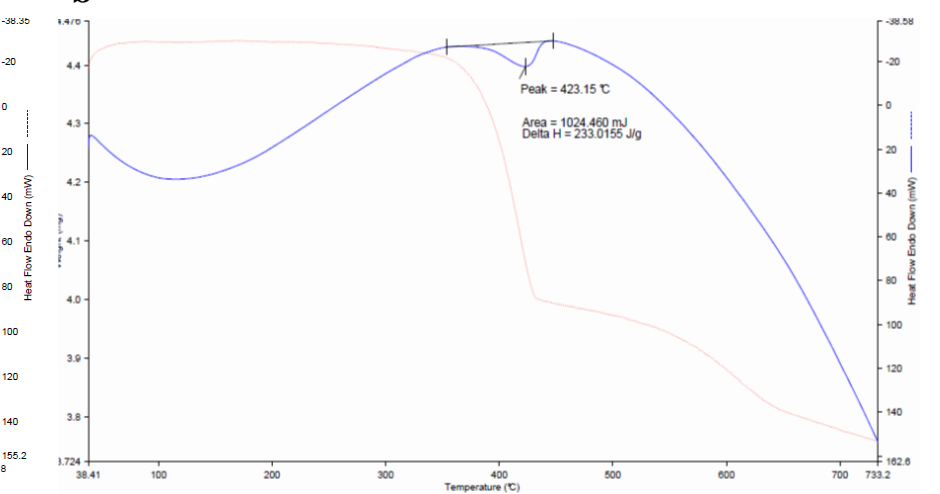

d

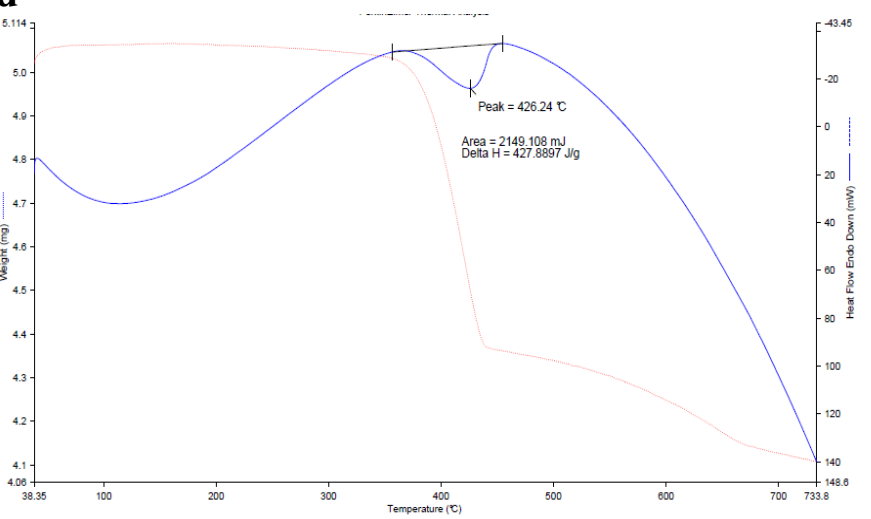

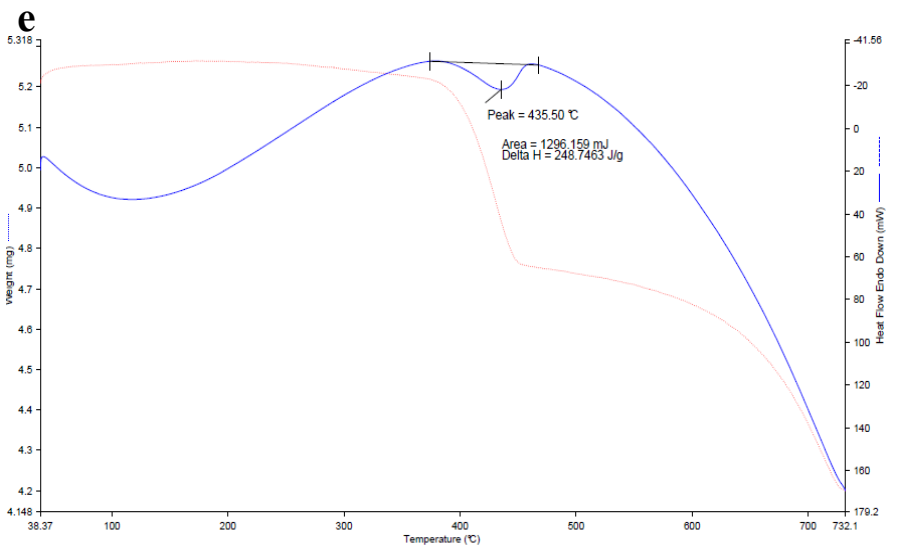

Figure 3: TGA curves of Pure HAp and Ni doped HAp powders.

\begin{tabular}{|c|c|c|c|c|c|}
\hline Samples & Ca & P & O & H & Ni \\
\hline Pure HAp & 45.10 & 3.70 & 51.20 & - & - \\
\hline $2 \%$ Of Ni & 67.12 & 1.85 & 28.59 & 1.44 & 1.00 \\
\hline $4 \%$ Of Ni & 49.26 & 5.05 & 38.99 & 3.55 & 3.15 \\
\hline $6 \%$ Of Ni & 31.10 & 9.85 & 47.40 & 4.42 & 6.42 \\
\hline $8 \%$ Of Ni & 39.89 & 3.83 & 41.55 & 8.30 & 7.90 \\
\hline
\end{tabular}

Table 3: Elemental composition of pure HAp and Ni doped HAp samples.

\section{SEM analysis (scanning electron microscope)}

SEM data was collected at Gandhigram University, Dindugal. SEM can achieve resolution better than 1 nanometer [9]. The SEM images are shown in Figure 5. Structural variations are observed for the undoped and $\mathrm{Ni}$ doped hydroxyapatite nanostructures.

\section{TEM analysis (transmission electron microscopy)}

TEM analysis has been done at SAIF, COCHIN. The structure and morphology of the samples were confirmed by the TEM images of the prepared nano-hydroxyapatite. The transmission electron microscopic analysis confirms the presence of the spherical shape morphology of the prepared hydroxyapatite nanoparticle with the particle size of around 20 to $100 \mathrm{~nm}$. The topographical information near the surface of pure hydroxyapatite and $\mathrm{Ni}$ doped samples were examined by using TEM (Figures 6 and 7).

\section{Antibacterial activity of compounds against microbial} pathogen

The antibacterial activity of components against microbial result 
Citation: Saranya S, Muthuselvi S, Prema Rani M (2018) Structural, Optical and Antimicrobial Analysis of Nickel Doped HAp Synthesized by Solgel Method for Biomedical Applications. J Material Sci Eng 7: 413. doi: 10.4172/2169-0022.1000413
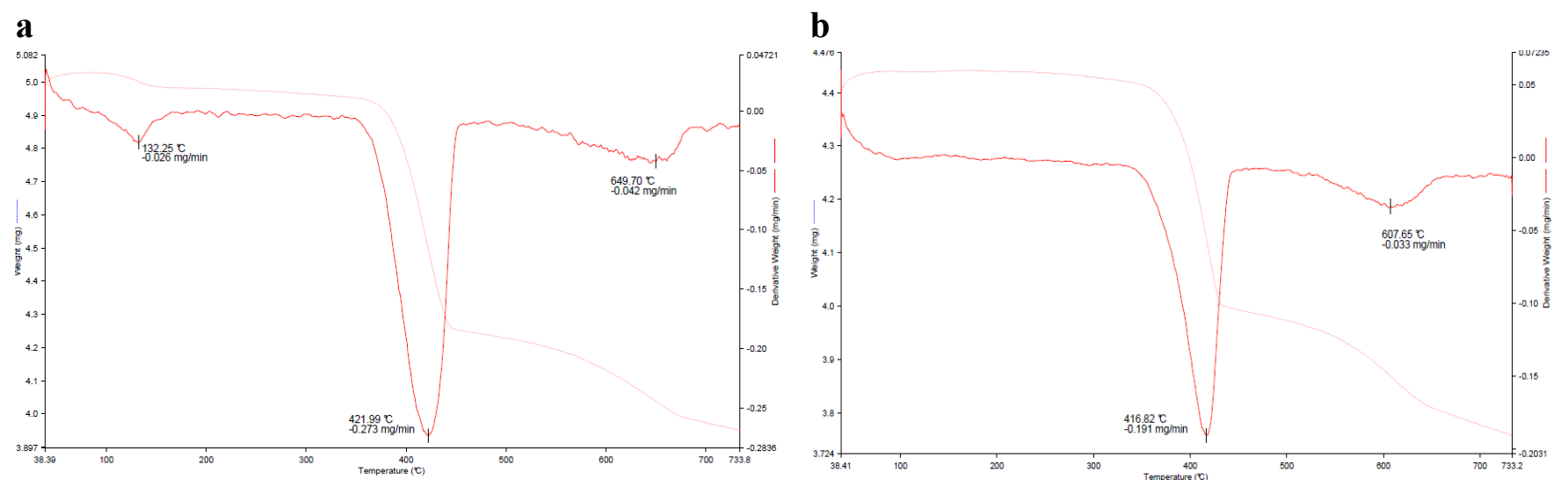

c

d
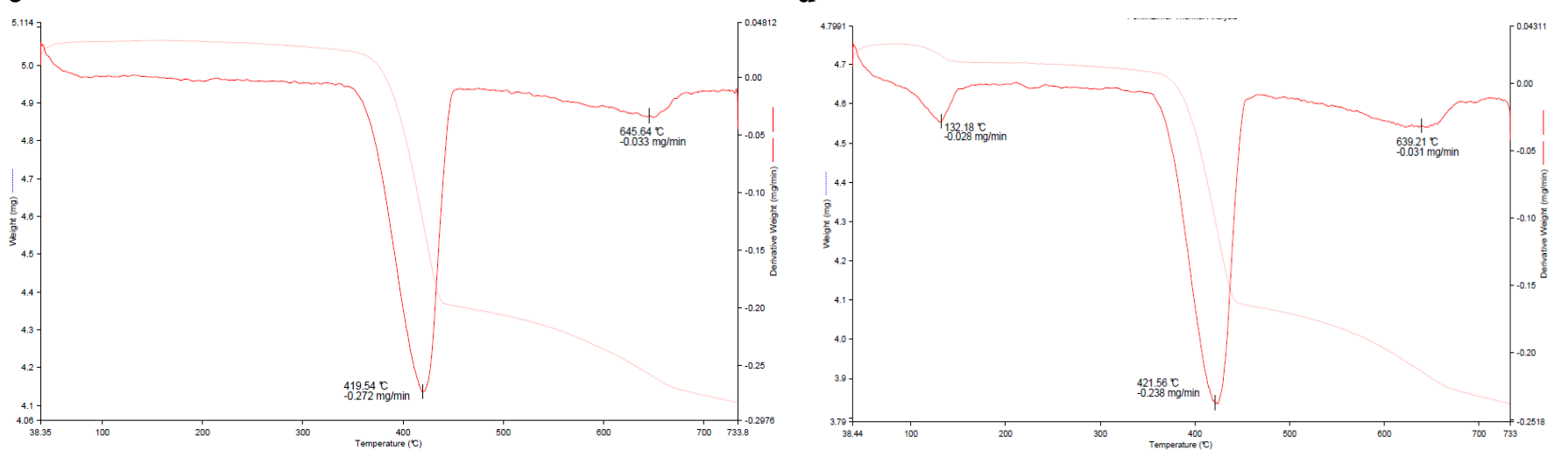

\section{e}

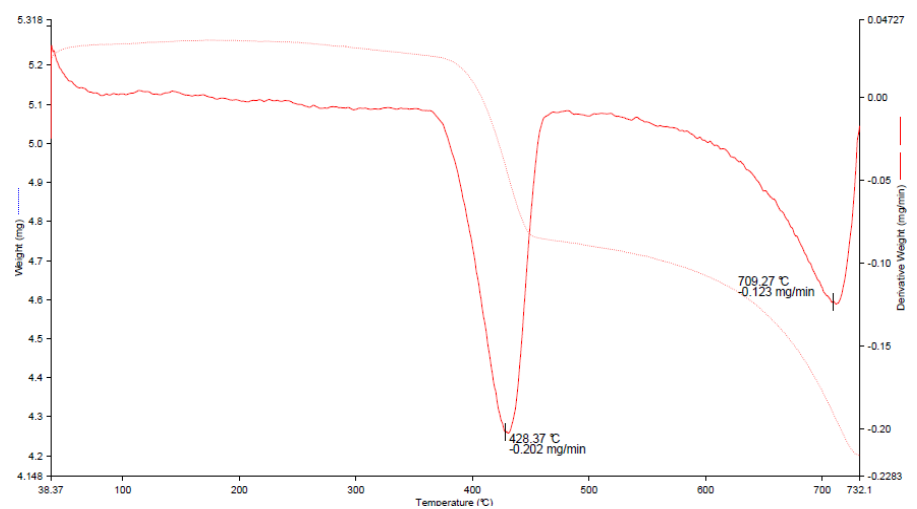

Figure 4: DTA curve of Pure HAp and Ni doped HAp powders.

\begin{tabular}{|c|c|c|c|c|c|c|}
\hline \multicolumn{5}{|c|}{ Wave number $(\mathrm{cm})^{-1}$} & \multirow[t]{2}{*}{ Functional group } & \multirow[t]{2}{*}{ Type of vibrational mode } \\
\hline Pure & $2 \% \mathrm{Ni}$ & $4 \% \mathrm{Ni}$ & $6 \% \mathrm{Ni}$ & $8 \% \mathrm{Ni}$ & & \\
\hline 3642.48 & 3642.28 & 3642.61 & 3642.73 & 3642.28 & $\mathrm{O}-\mathrm{H}$ & Stretching \\
\hline 3572.63 & 3572.71 & 3573.91 & 3572.15 & 3574.71 & $\mathrm{O}-\mathrm{H}$ & Stretching \\
\hline 1486.56 & 1466.22 & 1471.27 & 1471.37 & 1471.22 & $\mathrm{CO}_{3}$ & Asymmetric \\
\hline 1095.20 & 1094.20 & 1050.18 & 1094.82 & 1094.82 & $\mathrm{C}-\mathrm{O}$ & Stretching \\
\hline 962.09 & 962.49 & 962.59 & 962.47 & 962.49 & $\mathrm{PO}_{4}$ & Symmetric \\
\hline 637.84 & 637.00 & 632.87 & 632.00 & 632.00 & $\mathrm{O}-\mathrm{H}$ & Stretching \\
\hline - & 603.48 & 603.10 & 603.65 & 602.91 & O-P-O & Bending \\
\hline
\end{tabular}

Table 4: Functional group analysis of pure HAp and Ni doped HAp powders. 
Citation: Saranya S, Muthuselvi S, Prema Rani M (2018) Structural, Optical and Antimicrobial Analysis of Nickel Doped HAp Synthesized by Solgel Method for Biomedical Applications. J Material Sci Eng 7: 413. doi: 10.4172/2169-0022.1000413

Page 5 of 7

\begin{tabular}{|l|c|c|c|c|c|}
\hline \multirow{2}{*}{ Test organisms } & \multicolumn{4}{|c|}{ Zone of inhibition in millimeter(in diameter) } \\
\cline { 2 - 4 } & Pure HAp & $\mathbf{2 \%} \mathbf{~ N i}$ & $\mathbf{4 \%} \mathbf{~ N i}$ & $\mathbf{6 \%} \mathbf{~ N i}$ \\
\hline Shigella flexneri & 11 & 13 & 10 & 11 \\
\hline
\end{tabular}

$\mathbf{a}$

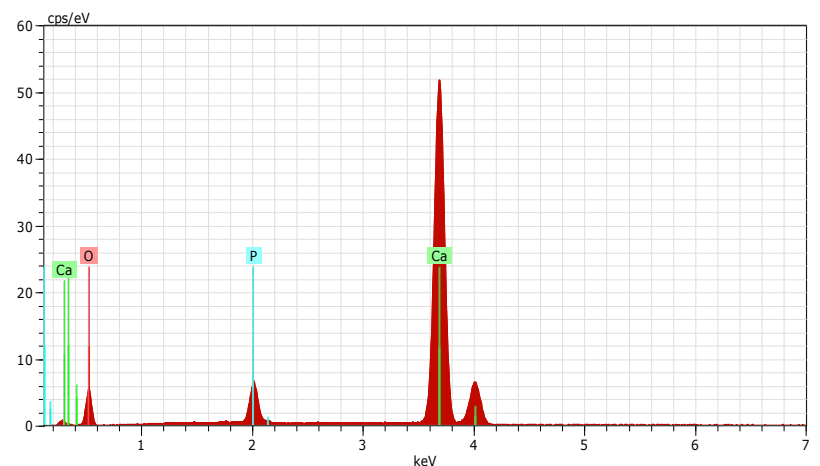

c

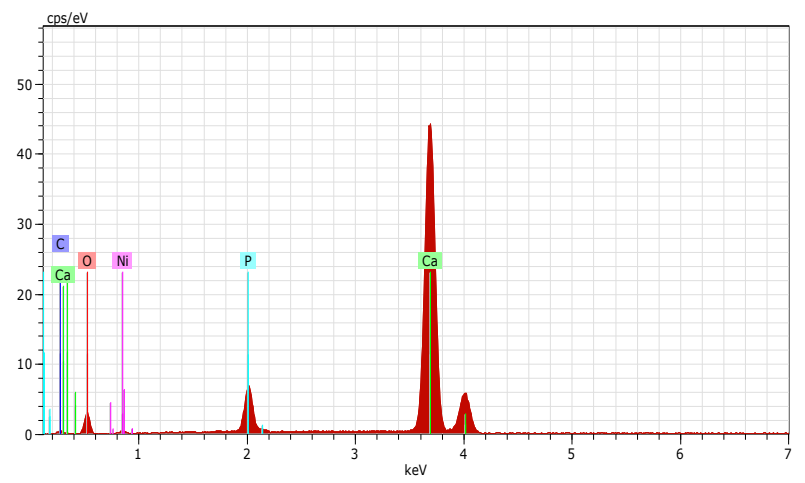

e

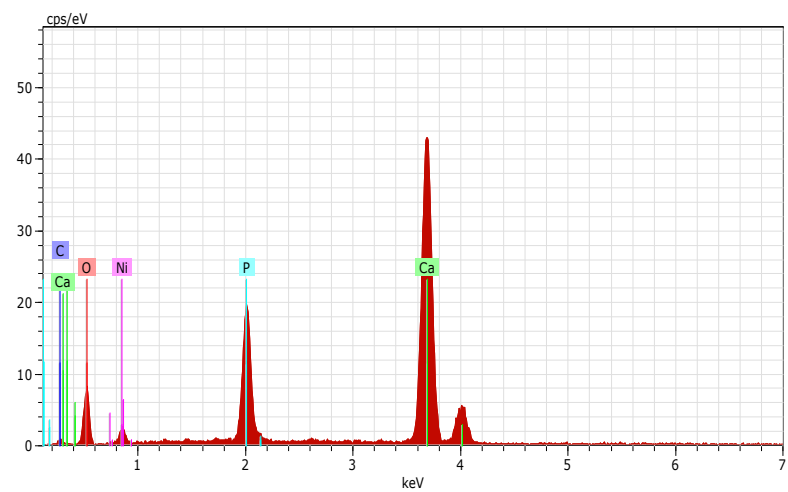

b

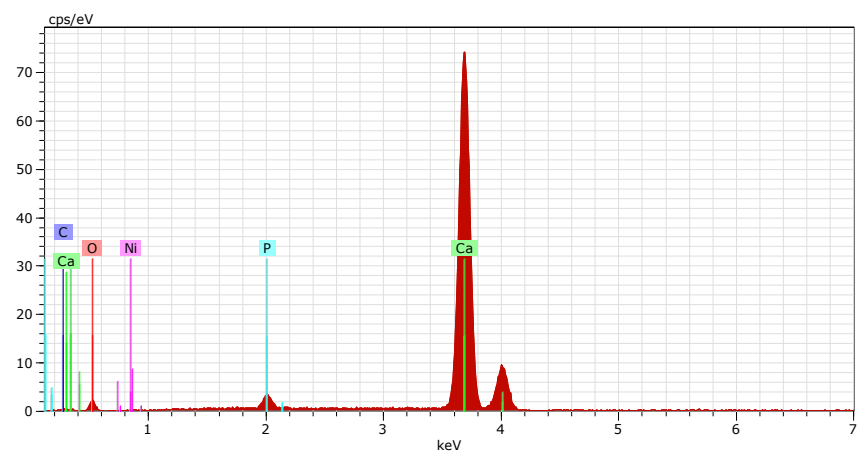

d

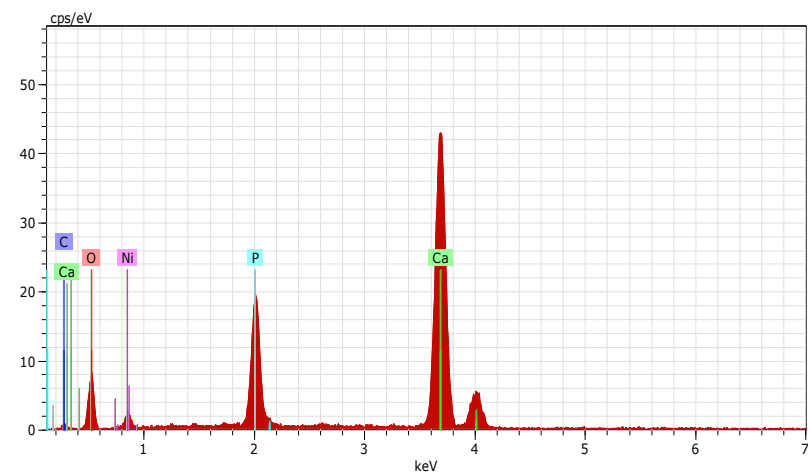

Figure 5: EDS Spectrum of Pure HAp and Ni doped HAp powders.

was has been done at Ventura Biotechnology lab Madurai. The antimicrobial activity of samples was tested against Shigella flexneri by sterilizing Mueller Hinton agar media. It was determined by well diffusion method. The plates were incubated at $30^{\circ} \mathrm{C}$ for 24 hours, and then the diameters of the zone of inhibition were measured in millimeters (Table 4, 5 and Figure 8).

\section{Conclusion}

The present study reveals that HAp powder can be synthesized by sol-gel method. X-ray diffraction and EDX analysis indicates the phase purity and crystallinity of the HAp powder. Doping of nickel is confirmed from EDX spectrum. Sol-gel method is very useful to synthesize the Ni doped bioceramics derived from hydroxyapatite. 
Citation: Saranya S, Muthuselvi S, Prema Rani M (2018) Structural, Optical and Antimicrobial Analysis of Nickel Doped HAp Synthesized by Solgel Method for Biomedical Applications. J Material Sci Eng 7: 413. doi: 10.4172/2169-0022.1000413
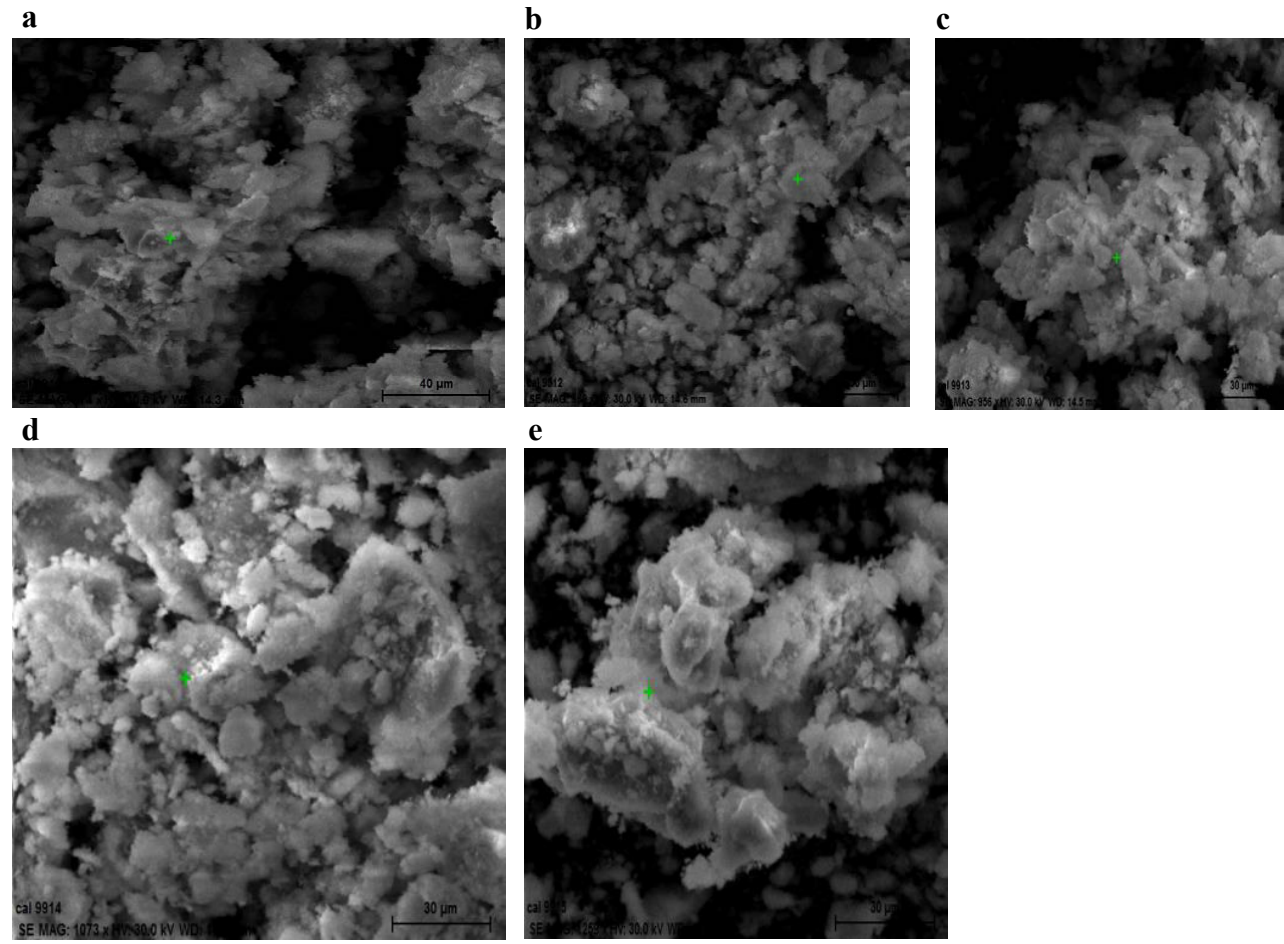

Figure 6: Surface Morphology of Pure HAp and Ni doped HAp powders.

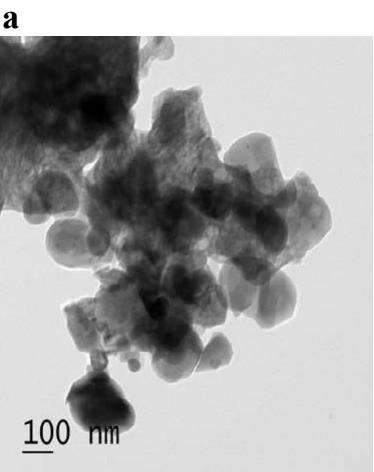

d

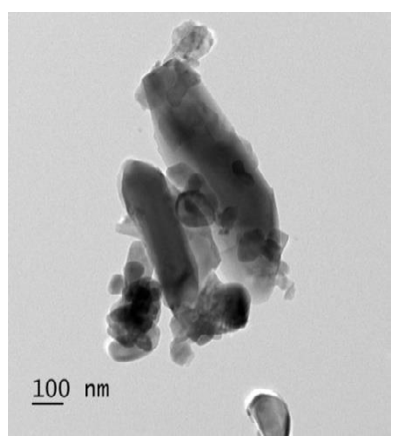

b

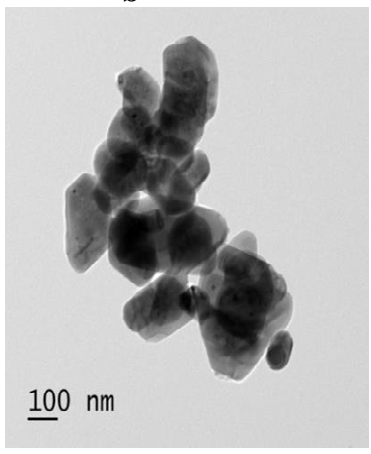

e

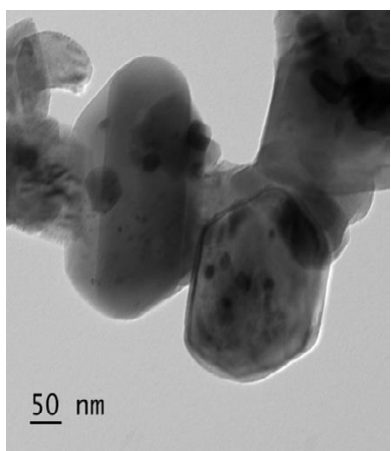

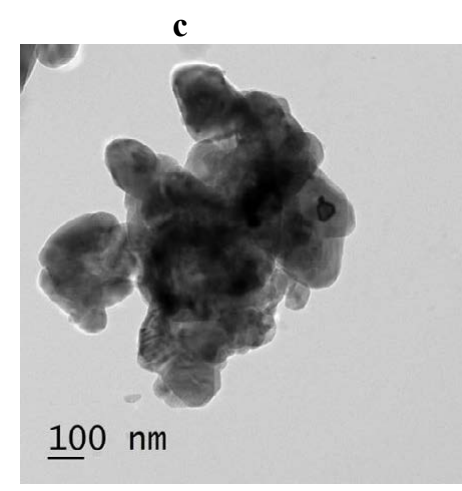

$100 \mathrm{~nm}$

Figure 7: TEM images of Pure HAp and Ni doped HAp powders. 
Citation: Saranya S, Muthuselvi S, Prema Rani M (2018) Structural, Optical and Antimicrobial Analysis of Nickel Doped HAp Synthesized by Solgel Method for Biomedical Applications. J Material Sci Eng 7: 413. doi: 10.4172/2169-0022.1000413

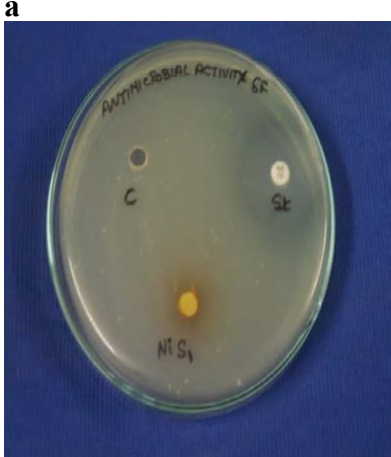

d

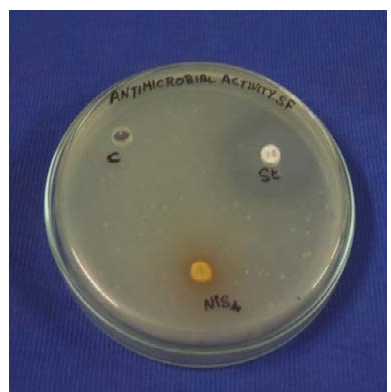

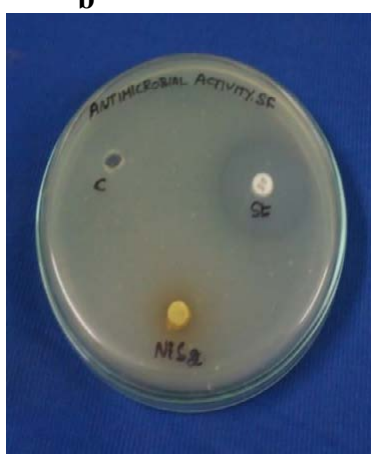

$\mathbf{e}$

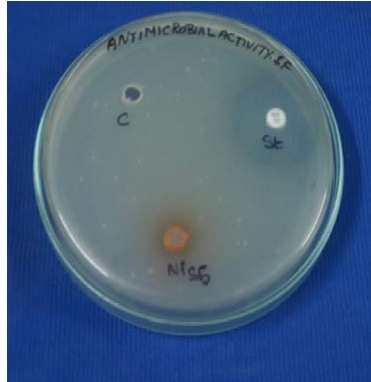

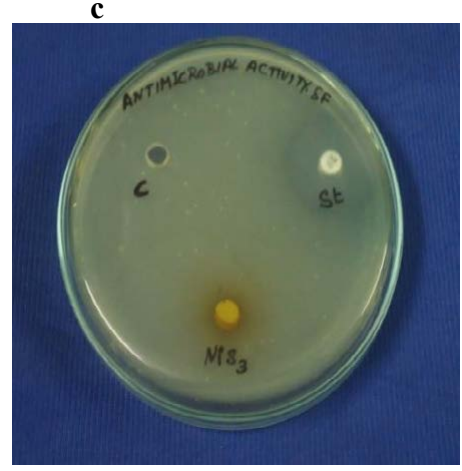

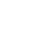

Figure 8: Antibacterial activity setup of Pure HAp and Ni doped HAp powders.

The crystallite size was calculated using full-width-at-half-maximum (FWHM) of the diffraction peaks. The crystallite size decreased in the case of $\mathrm{Ni}$ doped in hydroxyapatite. The reason may be that the ionic radius of $\mathrm{Ni}(200)$ is less than that of $\mathrm{Ca}$ (231) pm The FTIR spectra proved formation of HAp due to the present of $\mathrm{OH}$ Structural, $\mathrm{PO}_{4}$ symmetric stretching mode of phosphate functional groups. Structural morphology were observed from TEM analysis. From DTA and TGA analysis, the thermal stability of the samples were analysed. At higher temperatures the stability of the samples were found to decrease with increasing doping concentration. Antibacterial activity is highly preferred for materials used in medical implantation. Hence from the above analysis it is observed that $\mathrm{Ni}$ doped hydroxyapatite can be used for medical applications.

\section{References}

1. Weng W, Shen G, Han G (2000) Low temperature preparation of hydroxyapatite coatings on titanium alloy by a sol-gel route. Journal of Materials Science Letters 19: 2187-2188.

2. Cheng K, Weng W, Han G, Du P, Shen G, et al. (2003) The effect of triethanolamine on the formation of sol-gel derived fluoroapatite/hydroxyapatite solid solution. Materials Chemistry and Physics 78: 767-771.

3. Riman RE, Suchanek WL, Byrappa K, Chen CW, Shuk P, et al. (2002) Solution synthesis of hydroxyapatite designer particulates. Solid State lonics 151: 393-402.

4. Huang LY, Xu KW, Lu J (2000) A study of the process and kinetics of electrochemical deposition and the hydrothermal synthesis of hydroxyapatite coatings. Journal of Materials Science: Materials in Medicine 11: 667-673.

5. Baradaran S, Moghaddam E, Nasiri-Tabrizi B, Basirun WJ, Mehrali M, et al (2015) Characterization of nickel-doped biphasic calcium phosphate/graphene nanoplatelet composites for biomedical application. Materials Science and Engineering: C 49: 656-668.

6. Rocha JHG, Lemos AF, Kannan S, Agathopoulos S, Ferreira JMF (2005) Hydroxyapatite scaffolds hydrothermally grown from aragonitic cuttlefish bones. Journal of Materials Chemistry 15: 5007-5011.

7. BK (1991) X-ray Spectroscopy (2ndedn), Springer-verlag, Berlin.

8. Goldstein JI, Newbury DE, Michael JR, Ritchie NW, Scott JHJ, et al. (2017) Scanning electron microscopy and X-ray microanalysis. Springer.

9. http://sec.carleton.edu/research_education/techniques/SEM.html 